\title{
EL TÍTULO V DE LA LOTC Y EL DENOMINADO PLAN IBARRETXE. COMENTARIO AL AUTO DEL TRIBUNAL CONSTITUCIONAL DE 30 DE ABRIL DE 2004
}

\author{
FERNANDO REVIRIEGO PICÓN \\ UNED
}

\section{INTRODUCCIÓN}

El pasado 20 de abril, el Tribunal Constitucional acordó la inadmisión a trámite y archivo de actuaciones de la impugnación acumulada que hiciera el Gobierno de la Nación tanto del Acuerdo del Gobierno Vasco, de 25 de octubre de 2003, como del Acuerdo de la Mesa del Parlamento Vasco, de 4 de noviembre del mismo año. Mediante aquél se había aprobado y dado traslado al Presidente del referido Parlamento de la "Propuesta de Estatuto Político de la Comunidad de Euskadi" (en adelante P.E.P.C.E.); mediante éste se había admitido a trámite la propuesta de reforma para su tramitación conforme al procedimiento legislativo ordinario, ordenando su remisión a la Comisión Parlamentaria de Instituciones e Interior y abriendo el plazo correspondiente para la presentación de enmiendas. Hablamos, claro está, del proyecto que se ha venido en denominar comúnmente como "Plan Ibarretxe», eje referencial ineludible del debate político de los últimos tiempos.

Si bien estaríamos tentados a calificar el resultado del proceso como la crónica de una inadmisión anunciada, derivado de "una impugnación equivocada» como la vino a definir al poco de su interposición el actual Presidente del Consejo de Estado $^{1}$, lo cierto es que ahora bien podríamos estar reseñando en estas notas una resolución completamente diferente. Esto es así porque la decisión de la inadmisión no fue pacífica en el seno del Tribunal. Ni mucho menos. Más aún, suscitó por el contrario una fuerte división, no en vano cinco de los doce magistrados manifestaron una tesis contraria a la inadmisión finalmente acordada, suscribiendo diferentes votos particulares a la sentencia. Entre estos últimos se encontraba incluso el entonces Presidente; de esta

1. RUBIo LloRENTE, F., "Una impugnación equivocada", EL PAÍS, 8 de noviembre de 2004. 
forma, por mor de su voto de calidad, si uno sólo de los otros siete se hubiera adherido a la tesis de la admisibilidad, como ya hemos apuntado, el escenario sería otro bien distinto.

Un trámite, el de admisión, que habitualmente suele realizarse con mayor celeridad, necesitó en este supuesto, polémico y de especial complejidad, casi seis meses; recordemos que la impugnación, acordada por el Consejo de Ministros en su reunión de 7 de noviembre de 2003, se presentó ante el Tribunal pocos días después. Las elecciones, primero, y la posibilidad de que el nuevo Gobierno pudiera retirar el recurso tras la toma de posesión, se barajaron en diferentes ámbitos, y entre otros argumentos, como las razones de dicho retraso. En todo caso, poco habitual.

\section{EL CONTENIDO DEL PLAN Y SU TRAMITACIÓN}

Conocido es de todos, con mayor o menor detalle, dada su amplia difusión por diferentes medios, el contenido, o cuando menos las líneas generales y esenciales, de este Plan, articulado en seis títulos y un total de sesenta y nueve artículos ${ }^{2}$. Pese a ello, apuntaremos una breve reseña del mismo.

El amplio Título Preliminar da comienzo con la previsión de la fórmula de la constitución de la Comunidad vasca libremente asociada al Estado Español bajo la denominación de Comunidad de Euskadi. Inmediatamente a continuación se contempla el ámbito territorial de dicha Comunidad, sus símbolos, la extensión de la ciudadanía y nacionalidad vasca, las relaciones con la Comunidad Foral de Navarra (para la que, se aclara, no habrían de ser aplicables las previsiones del art. 145 C.E.) y los territorios vascos de Iparralde (territorios vasco-franceses), los valores del Autogobierno vasco, determinaciones sobre los derechos y deberes fundamentales de la ciudadanía vasca, así como previsiones sobre ciudadanos vascos residentes en el exterior bajo la llamativa y poco feliz rúbrica "diáspora vasca».

El Título I, por su parte, establecerá de manera más específica las implicaciones del régimen de relación política con el Estado español (el famoso estatus de libre asociación, a la búsqueda todavía de su modelo) y sus garantías de autogobierno. Entre éstas cabría destacar aquí la creación de una Sala Especial del Tribunal Constitucional (constituida como Tribunal de Conflictos Euskadi-Estado) que conocería en exclusividad de los procedimientos de declaración de inconstitucionalidad y de los conflictos constitucionales que pudieran suscitarse en relación con las Instituciones y Poderes de la Comunidad de Euskadi. De igual forma, y en orden a garantizar el principio de equilibrio de poderes se establece que la impugnación por el Gobierno de disposiciones normativas y resoluciones adoptadas por instituciones vascas no suponga su suspensión automática. Se excluirá también la aplicación de los controles extraordinarios del art. 155 C.E de una manera un tanto curiosa, ya 
que señala que "no resultará de aplicación unilateral por parte del Estado". Apuntar la exclusión de este control es una cosa, pero hacerlo incorporando tal coletilla raya en el absurdo, en tanto que no estamos sino ante una última ratio por el incumplimiento de una Comunidad Autónoma y que, entre otras cuestiones, precisa que el Presidente de la misma desatienda el requerimiento previo necesario. Por último, llama la atención que la posibilidad de reforma del (futurible) Estatuto Político se contemple en este mismo Título.

El Título II, uno de los más extensos, aborda la regulación de los diferentes poderes. De aquí cabría resaltar la creación del Consejo Judicial Vasco que ejercería el gobierno del Poder Judicial en el ámbito de la Comunidad. Este Consejo, encargado entre otras funciones de designar al Presidente del Tribunal Superior de Justicia, inspección de Juzgados y Tribunales, consulta e informe sobre las materias que afecten al Poder Judicial en dicha Comunidad, etc., estará integrado por el Presidente del Tribunal Superior de Justicia y por un conjunto de miembros (la cifra se difiere a su previsión en sede legal) elegidos entre Jueces y Magistrados que ejerzan sus funciones en la Comunidad de Euskadi.

En el Título III, de apenas seis artículos, se establecería el Régimen de relación política e institucional en el ámbito de la Comunidad, así, las Instituciones Vascas, capitalidad, etc.

El ejercicio del poder público y las previsiones competenciales se regulan en el siguiente Título (IV) que sería el más amplio de la Propuesta. Como competencias exclusivas del Estado, en su relación con la Comunidad de Euskadi, quedarían la nacionalidad española, extranjería y derecho de asilo (eso sí, precisemos, "sin perjuicio del carácter compartido de las políticas de emigración e inmigración, en función de su incidencia en las políticas sectoriales exclusivas de la Comunidad de Euskadi, como apuntaría el art. 45.1.a P.E.P.C.E.), la Defensa y Fuerzas Armadas y el régimen de producción, comercio, tenencia y uso de armas y explosivos. También, el sistema monetario, el régimen aduanero y arancelario (no el comercio exterior del 149.1.10 C.E., como vemos), la marina mercante y el abanderamiento de buques, matriculación de aeronaves y control del espacio aéreo, así como las relaciones internacionales ( sin perjuicio de las actuaciones con repercusión exterior que se reconocen a la Comunidad de Euskadi en este Estatuto" - art. 45.1.g. P.E.P.C.E.-). Como podemos observar, aunque no en su totalidad, respetaría aquí algunas (pocas) de las determinaciones del art. 149 C.E., concretamente sus apartados 2, 3, 4, $10,11,20$ y 26. Junto a ello, señalará que corresponderá al Estado, en calidad de legislación común ( sin perjuicio de la capacidad de las Instituciones vascas para su desarrollo y adaptación a su derecho sustantivo, así como para su aplicación y ejercicio de las potestades de ejecución que correspondan" - art. 45.2 P.E.P.C.E.-) las materias de legislación penal, penitenciaria y procesal, $-s i n$ perjuicio de las peculiaridades del derecho sustantivo vasco-, legislación mercantil, — sin perjuicio de las bases de las obligaciones contractuales de carácter mercantil, asi como en su caso de las bases de los contratos y concesiones administrativas -, legislación civil, _ sin perjuicio del derecho privado civil o foral o propio de Euskadi - legislación de propiedad intelectual e industrial y en 
materia de pesas y medidas, contraste de metales y determinación de la hora oficial (ver art. 149 C.E., apartados 6, 8, 9 y 12). Inmediatamente a continuación de esta enumeración establecerá las competencias que de manéra exclusiva corresponderán a la comunidad de Euskadi, que dividirá entre políticas públicas exclusivas de "régimen general" y de "régimen específico". Entre aquéllas se contarían las políticas de institucionalización y autogobierno, educativas y culturales, sociales y sanitarias, sectoriales, económicas y financieras, de recursos naturales, ordenación territorial, vivienda y medio ambiente, de infraestructuras y transportes; entre éstas, las políticas de seguridad pública, socio-laborales y de empleo, así como de protección social.

La regulación de la Economía, Hacienda y Patrimonio de la Comunidad de Euskadi quedará regulada en el Título V, mientras que el régimen de relación política con el ámbito europeo e internacional (relaciones con Europa, relaciones exteriores y cooperación al desarrollo) se hará en el Título VI y último. Por lo que a la Unión Europea haría referencia se establecen varias cuestiones. Por un lado, que la Comunidad de Euskadi disponga de representación directa en los órganos de la Unión Europea. Por otro, que se conforme una circunscripción electoral única en el ámbito de las elecciones al Parlamento Europeo; recordemos que esta última es una pretensión recurrente en diferentes Legislaturas a iniciativa lógicamente de diversos grupos nacionalistas, entre ellos el propio Grupo Vasco. Por lo que al Tribunal Europeo de Justicia haría referencia se establece la necesidad de que el Estado garantice el acceso de las Instituciones Vascas al mismo "en tanto en cuanto no se encuentre previsto su acceso directo en la normativa europea" (art. 65.5 P.E.P.C.E.).

Finalmente, el Proyecto se cierra con una disposición transitoria que establece un plazo máximo de seis meses en orden a asumir las potestades, funciones y servicios establecidos en el P.E.P.C.E. y una disposición final en la que únicamente se apuntaría que éste sucederá y sustituirá al Estatuto de Autonomía del 79.

A la vista de todo ello (aunque sólo hemos apuntado algunas cuestiones), y como se ha señalado repetidamente, ni estamos ante una reforma del Estatuto ni de la Constitución, sino ante una suerte de propuesta constituyente originaria. Señalará así F. RUBIO LLORENTE que "Algunos de los cambios competenciales que propone quedan más allá el marco constitucional. La diferencia estriba sin embargo en el hecho de que, en tanto que sería posible reformar la Constitución para que las CC.AA. adquiriesen competencias que hoy no pueden tener, no me parece posible una reforma que niegue la soberanía del pueblo español sobre la totalidad del territorio nacional. Haya o no cláusulas expresas de intangibilidad, no todo en una Constitución es reformable. Hay reformas que son imposibles por contradictorias con la idea misma de Constitución, o simplemente con la lógica $n^{3}$. Por su parte, para $\mathrm{P}$. González-Trevijano esta Propuesta "va mucho más allá de lo que es la trami- 
tación de un procedimiento de reforma estatutaria, pues implica, en realidad, dada la subversión de principios y valores constitucionales enunciados, una revisión constitucional in integrum de los postulados constitucionales vigentes de nuestro mismo modelo de distribución territorial del poder políticon encontrándonos ante un "problema que alcanza a los límites conformadores de los principios de unidad del Estado español y de autonomía de las CC.AA.." En el mismo sentido, E. Vírgala Foruria, apuntará que "no es que la misma (propuesta) sea inconstitucional, sino que está al margen de la Constitución, ha sido realizada como si la de 1978 no existiera (..) no se trata de una reforma de la Constitución, sino de un cambio de Constitución ${ }^{5}$.

Hasta aquí, una descripción concisa del contenido de una propuesta que en plazos, teóricamente y según sus proponentes, debería culminar en el otoño de 2004 con su eventual debate y aprobación, así como con su votación en ese referéndum anunciado para la primavera de 2005 . A la fecha de cierre de estas líneas las últimas noticias son las comparecencias verificadas ante la Ponencia constituida para el estudio de la P.E.P.C.E. en la Comisión de Instituciones e Interior en fecha 30 de junio, y la última documentación remitida por el Gobierno Vasco, como aportación para el debate, el Informe "Razones económicas para un nuevo marco institucional. Un nuevo estatuto politico para desarrollar el crecimiento y el bienestar de la sociedad vasca" en el que se analiza el impacto económico del marco institucional propuesto.

A los efectos de estas notas, no parece preciso abundar más en una propuesta suficientemente conocida, que ya ha sido objeto de múltiples debates y constante estudio en diferentes foros ${ }^{6}$, cuya principal tacha de inconstitucionalidad como se ha referido (dentro del más de centenar de infracciones que contendría, a criterio de la Abogacía del Estado - a nosotros nos ha faltado la paciencia para contarlas-), sería la centrada en la violación de la cláusula constitucional de soberanía?.

Respecto de la tramitación, únicamente señalar que a esta propuesta, presentada formalmente como una reforma del Estatuto de Autonomía del País Vasco (art. 46.1.a E.A.), se le aplicaron finalmente las reglas del procedimiento legislati-

4. "Sobre la viabilidad procesal de la impugnación adoptada por el Gobierno frente al Acuerdo del Gobierno Vasco de 25 de octubre y de la Mesa del Parlamento Vasco adoptado en su reunión de 4 de noviembre de 2003 de conformidad con el procedimiento impugnatorio del art. 161.2 de la CE», pág. 6

5. "El Proyecto Ibarretxe: independentista, antidemocrático e inconstitucional", Cuadernos de Alzate, nº 29, 2003, pág. 60 .

6. Merece la pena destacar tanto las Jornadas de Estudio sobre la Propuesta del Lehendakari (más específicamente, la Propuesta política para la convivencia presentadas por éste en el debate de Política General del Parlamento Vasco en septiembre de 2002), organizadas por la Facultad de Derecho del País Vasco, y celebradas en febrero de 2003, como las Jornadas sobre Euskadi y su futuro institucional celebradas en abril de 2003 a instancias de a revista Cuadernos de Alzate. El contenido de las ponencias fue publicado finalmente en el volumen colectivo Estudio sobre la propuesta polttica para la convivencia del Lehendakari Ibarretxe, editada por el I.V.A.P. y en el $\mathrm{n}^{\circ} 28$ de los Cuadernos de Alzate respectivamente.

7. Como señaló la Abogacía del Estado en su escrito de impugnación, estaría estrechadamente enlazada con las de los arts. 2 y 168 CE y de la D.A. 1a CE. 
vo ordinario (no recoge el Reglamento del Parlamento el procedimiento para la reforma estatutaria), con la salvedad del requisito de la mayoría absoluta para su aprobación, remitiéndose así el texto, en primera instancia, a la Comisión de Instituciones e Interior. Destacar, de igual manera, la votación por separado de las tres enmiendas a la totalidad presentadas al proyecto, en las que se solicitaba la devolución del mismo al Gobierno, y que habían sido presentadas respectivamente por los Grupos Parlamentarios Popular y Socialistas Vascos, así como por Araba, Bizkaia eta Gipuzkoako Sozialista Abertzaleak. Frente a uno y otro acuerdo se presentaron sendas solicitudes de reconsideración, desestimadas todas ellas en última instancia. Señalar igualmente que tras el cambio de gobierno, y a la vista del Auto del Tribunal Constitucional, el propio Presidente del Parlamento Vasco llegó a apuntar la posibilidad de abrir nuevamente el trámite de enmiendas de cara a que desde el Grupo Socialista en el Parlamento Vasco se pudieran introducir enmiendas al Proyecto, propuesta desechada por éste ${ }^{8}$.

\section{LOS OBJETOS «IDÓNEOS"DE IMPUGNACIÓN: “DISPOSICIONES SIN FUERZA DE LEY Y RESOLUCIONES DE LAS COMUNIDADES AUTÓNOMAS".}

Más allá del contenido concreto de esta Propuesta, cuya inconstitucionalidad, tal y como se encuentra formulado a día de hoy, nadie discutiría, y de la propia tramitación seguida para su aprobación y su eventual fraude procedimental, el problema de fondo no es otro que entender si concurría o no el presupuesto procesal de constituir los dos acuerdos supra referidos "objetos idóneos de impugnación" al amparo de las previsiones del Título V de la L.O.T.C. Cotejar en consecuencia el mecanismo procesal escogido. Nada más; nada menos.

Este sería el elemento verdaderamente determinante. La ausencia de tal condición determinaría obviamente un presupuesto procesal insubsanable.

Partamos a tal efecto del tenor literal de los artículos 76 y 77 de la L.O.T.C. Contemplan éstos la posibilidad de impugnar por parte del Gobierno las "disposiciones sin fuerza de ley y resoluciones de las Comunidades Autónomas" a los que se impute un vicio de inconstitucionalidad que no consistiera en la infracción del orden constitucional de distribución competencial.

Estas previsiones, recordemos, derivaron de una interpretación amplia de la literalidad del art. 161.2 C.E., y que en su momento fueron calificadas por un sector de la doctrina, encabezado por F. Rubio Llorente y M. Aragón Reyes, de incongruentes con nuestro sistema de control, distorsionadoras o de dudosa constitucionalidad ${ }^{9}$. Como se ha señalado en reiteradas ocasiones, parecía buscarse de algúna manera que ninguna disposición normativa o acto de las

8. Cfr. EL PAIS, 30 de abril de 2004, pág. 20.

9. RuBio Llorente, F., ARAGón REYES, M., "La jurisdicción constitucional",La Constitución Española de 1978. Estudio sistemático, PEDRIERI A., GARCía DE ENTERRIA, E., Madrid, 1981, págs. 885/886. También durante los primeros años de vigencia de la L.O.T.C., DiEz MORENO, F., "El control cons- 
Comunidades Autónomas pudiera terminar escapando al control del Tribunal Constitucional y, a la eventual suspensión automática de su vigencia. Destaca A. Pascual Medrano que esta impugnación "hay que entenderla dentro del contexto de nuestra concreta organización territorial, marcada por una significativa ausencia de controles de tipo político, lo que, en el fondo, se compensó, en sede constituyente, con la introducción (..) del art. 161.2. El legislador orgánico lo que hace simplemente es dotar a dicho precepto de una proyección completa, máxima. Con independencia de los procedimientos ya previstos constitucionalmente, parece claro que no se quería dejar escapar la posible aplicación de la facultad de control otorgada por el 161.2 en ningún supuesto, por residual o excepcional que éste fuera en la práctica ${ }^{10}$.

Dicho lo anterior, habría que plantearse si cabría entender así que estos acuerdos referidos se incardinarían o no dentro de ese tenor literal; esto es, si cabría realizar una interpretación extensiva tal que se incluyeran tanto el acuerdo del Gobierno vasco como el del Parlamento teniendo en cuenta, no nos olvidemos, que nos encontraríamos evidentemente ante actos integrantes de un procedimiento legislativo ${ }^{11}$, o si por el contrario deberíamos apelar a una interpretación mucho más estricta de la misma, en la acotación de sus cabales límites ${ }^{\mathbf{1 2}}$.

titucional de la potestad normativa de las Comunidades Autónomas", El Tribunal Constitucional, (I), I.E.F., Madrid, 1981, págs. 727 y ss; o MuÑoz MACHADO, S.; Derecho Público de las Comunidades Autónomas (II), Cívitas Madrid, 1984, pág. 304. Con posterioridad en el tiempo, véase, ARAGón ReYes, M., "Artículo 161. Competencias del Tribunal Constitucional", Comentarios a la Constitución Española de 1978, Tomo XII, Cortes Generales-Editoriales de Derecho Reunidas, Madrid, 1999, pág. 248. En sentido contrario, por ejemplo, García de EnTERría, E., La Constitución como norma y el Tribunal Constitucional, Cívitas, Madrid, pág. 149 y ss; Fernández FARrERES, G., "La impugnación prevista en el artículo 161.2 de la Constitución y el problema de su sustantividad procesal", Revista Española de Derecho Constitucional, no 13, 1985, pág. 134; Pascual Medrano, A., La suspensión de actos y normas de las Comunidades Autónomas en la jurisdicción constitucional: el articulo 161.2 de la Constitución Española, Aranzadi, Madrid, 2001, pág. 154

10. La suspensión de actos y normas de las Comunidades Autónomas.., cit., pág. 160. Ver, también, Gómez MonTORO, A.J., Jurisdicción y procesos constitucionales, McGrawHill, Madrid, 1997, pág. 119.

11. La eventual caracterización de estas disposiciones como "actos de trámite" ha sido caballo de batalla de muchas de las reflexiones doctrinales que sobre esta cuestión se han articulado. Así, por ejemplo, cabría citar los Informes, elaborados para abordar la viabilidad procesal de la impugnación, por J.A. SANTAMARíA PASTOR ("Los actos de trámite ante el Tribunal Constitucional -con una advertencia final sobre la peligrosa práctica de las importaciones no selectivas"), P. GONZÁLEZ-TREVIJANO ("Sobre la viabilidad procesal de la impugnación..., cit..); O T.R. FERNÁNDEZ ("Sobre la viabilidad juridica de la impugnación por el Gobierno de España, al amparo del art. 161.2 CE, del acuerdo del Gobierno Vasco de 25 de octubre de 2003, aprobatorio de la propuesta de Estatuto politico de la Comunidad de Euskadi y del acuerdo adoptado por la Mesa del Parlamento Vasco el 4 de noviembre siguiente en orden a la tramitación de dicha propuestai). Este último Informe, aunque con la rúbrica «Sobre la viabilidad de la impugnación jurisdiccional del Plan Ibarretxe» se publica en este mismo número de la revista Teoría y Realidad Constitucional.

12. T. R. FERNÁnDEZ, en su minucioso informe sobre esta cuestión, y partiendo de una interpretación muy amplia del término resolución conforme la jurisprudencia constitucional (comprendería "no sólo los actos que ponen fin a un procedimiento, sino también los actos de trámite, incluso no cualịficados"), señalará que "Si no se tratara de un asunto tan estruendoso como el que ahora nos ocupa, no se plantearía siquiera el problema, desde la claridad de la doctrina constitucional (..), por lo que con el mero recordatorio de esta, la cuestión podría darse por zanjada sin más", "Sobre la viabilidad juridica de la impugnación..., cit., pág. 8. A. RODRíguez BEREIJo, por su parte, apuntará que nos encontramos ante un "caso paradigmático, 
Como sugerentemente expresa J.A. Santamaría Pastor, "tras casi veinte años de paz octaviana, el artículo 161.2 se erige nuevamente en piedra de escándalo en el concreto aspecto de su objeto, que hasta el momento no había dado lugar a reflexión dubitativa de ningún tipo, ¿Cuál es el significado del término resoluciones? El par de conceptos "disposiciones y resoluciones", ¿Comprende la totalidad de las actuaciones que pueden llevar a cabo, de una u otra forma, los órganos de una Comunidad Autónoma - leyes aparte, claro está- o, por el contrario, cabe detectar decisiones o actuaciones materiales insusceptibles de impugnación por esta vía?»13.

Previo a este análisis, que habrá de hacerse de forma independiente para cada uno de los dos acuerdos impugnados, parece preciso realizar un breve apunte de las disposiciones sin fuerza de ley o resoluciones impugnadas hasta la fecha conforme este procedimiento.

\section{ACUERDOS IMPUGNADOS AL AMPARO DEL TÍTULO V L.O.T.C.}

Ni que decir tiene que, más allá de su lógica sustantividad propia, el procedimiento del Título $\mathrm{V}$ de la L.O.T.C. tiene por su propia caracterización un carácter residual.

Recordemos que procede en los supuestos de vulneraciones constitucionales (no meramente legales) por razones extracompetenciales, como así se ha encargado de destacarlo el Tribunal Constitucional pese a la "indefinición legal de los motivos impugnatorios" recogidos en el art. 77.1 de dicha Ley en este sentido; podríamos citar a título de ejemplo, la S.T.C. 64/90, de 5 de abril.

Ello, no obstante, más allá de una práctica jurisprudencial que sería calificada por algunos de flexible a la vista de la más reciente S.T.C. 184/1996, de 14 de noviembre. Llegó a admitirse aquí una impugnación al amparo del Título V de la L.O.T.C. basada en motivos competenciales de manera exclusiva y no ya siquiera a través de una impugnación principal a través del conflicto de competencias y subsidiariamente respecto de éste o acumulada junto a un recurso de amparo, como así sucedió en otras ocasiones (cabría apuntar ejemplificativamente las S.S.T.C. 16/1984, de 6 de febrero, 102/1988, de 8 de junio o 158/1988, de 15 de septiembre). Aquella sentencia del 96, a juicio de G. FERNÁNDEZ FARRERES, no hizo sino introducir "Confusión en una cuestión que podría considerarse ya definitivamente resuelta. Una confusión, además, absolutamente innecesaria, por cuanto, en última instancia, hubiera bastado con subsanar, mediante el oportuno trámite, la calificación de la acción ejercitada,

canónico se podría decir, de aplicación de las singulares previsiones constitucionales contempladas en el art. 161.2 CE como remedio último de control político, mediante la jurisdicción constitucional, de unas resoluciones que atacan el fundamento mismo de la Constitución que libremente los españoles nos hemos dado", "La defensa de la Constitución ante el Tribunal Constitucional", pág. 5.

13. "Los actos de trámite ante el Tribunal Constitucional.., cit., pág.10. 
que no era otra que un verdadero y efectivo conflicto de competencia positivo" ${ }^{14}$. En el Auto que ahora comentamos, el Tribunal Constitucional se limitará a apuntar, que ha sido doctrina consolidada que este proceso únicamente permite la denuncia de vicios de inconstitucionalidad distintos de los derivados de la invasión competencial, si bien apunta igualmente el supuesto conocido por la sentencia arriba referida, reseñando que se trata de una interpretación que no se ha "consolidado con claridad" (F.J. 6). Quizá se pueda echar de menos aquí que el Tribunal hubiera despejado definitivamente esta específica cuestión mediante un juicio mucho más categórico.

En todo caso, como valoración de conjunto, para P. Pérez Tremps y E. AJA, frente a los temores iniciales de desbordamiento "hay que felicitarse sin reparos en la buena delimitación realizada respecto del procedimiento previsto en el Título V L.O.T.C." ${ }^{15}$.

Apenas en una decena de ocasiones ha debido conocer el Tribunal Constitucional supuestos de este tipo. Ello desde aquella impugnación, ya lejana, de la Resolución del Presidente de la Generalidad de Cataluña mediante la que se prestaba aprobación al Convenio, no fechado, adoptado con el Presidente del Consejo Regional de Murcia, relativo a la participación y cooperación en cuantas situaciones afectaran a las aspiraciones y necesidades comunes a ambas colectividades, que finalmente sería declarado nulo por el Tribunal, en su S.T.C. 44/1986, de 17 de abril. No obstante, y si bien esta fue la primera ocasión en que se impugnó de manera directa al amparo del Título $\mathrm{V}$ de la L.O.T.C., no podemos dejar de señalar que ya se había hecho uso de manera previa de este procedimiento, aunque subsidiariamente al planteamiento de un conflicto constitucional de competencias, respecto del Decreto del Consejo Ejecutivo de la Generalidad de Cataluña 346/1981 (S.T.C. 54/1982, de 26 de julio) ${ }^{16}$.

Hasta la fecha, la práctica había posibilitado la impugnación de disposiciones normativas como Ordenes ${ }^{17}$ o Decretos ${ }^{18}$, especialmente estos últimos. De

14. "Artículo 76", Comentarios a la Ley Orgánica del Tribunal Constitucional, J.L. ReQueijo (Coord.), T.C.-B.O.E., Madrid, 2001, pág. 1231. En el mismo sentido, A.. Pascual Medrano señala que el Tribunal sorprende con un aparente cambio de posición con una postura que a su juicio resultaría incorrecta, en tanto que el Título V L.O.T.C. tendría el sentido de permitir el control de constitucionalidad sobre normas o actos de los órganos de las CC.AA. que bien por su rango o por el carácter del vicio impugnado no tendrían acceso a dichos procedimientos (recursos de inconstitucionalidad, conflictos de competencia), La suspensión de actos y normas de las Comunidades Autónomas., cit., págs. 171/172.

15. "Tribunal Constitucional y organización territorial del Estado Autonómicon, La justicia constitucional en el Estado democrático, Tirant lo Blanch, Valencia, 2000, pág. 176

16. Ver también las S.S.T.C. 102/1988, de 8 de junio y 158/1988, de 15 de septiembre, y el A.T.C. $638 / 1986$, de 22 de julio.

17. "Orden de la Consejería de Educación de la Junta de Galicia, de 31 de agosto de 1987, por la que se daba desarrollo al Decreto 135/1983, de 8 de septiembre, sobre aplicación para la enseñanza de la Ley de Normalización Lingüística” —A.T.C. 189/1987, de 3 de junio-; “Orden de la Consejería de Agricultura, Ganadería y Montes, de la Junta de Castilla y León, de 7 de enero de 1988, por la que se prohibía la venta de cangrejos vivos de río en el territorio de la Comunidad" - S.T.C. 66/1991, de 22 de marzo-.

18. "Decreto $146 / 1984$, de 10 de abril, del Consejo Ejecutivo de la Generalidad de Cataluña, por el que se aprobaba el Reglamento para el desarrollo de la Ley 3/1984, de 9 de enero, del 
igual forma, se ha admitido a trámite por el Tribunal Constitucional la impugnación de resoluciones o acuerdos que pondrían fin a un procedimiento, así, resoluciones del Presidente de una Comunidad Autónoma ${ }^{19}$, del Presidente $^{20}$ y la Mesa $^{21}$ de un Parlamento autonómico, haciéndose lo propio igualmente con relación a actos materiales de órganos de gobierno autonómicos ${ }^{22}$.

De todos ellos, el caso más conocido, sin duda, hasta el que ahora nos ocupa, fue el que daría origen a la S.T.C. 16/1984, de 6 de febrero, que tuvo su origen en la impugnación, en septiembre de 1983, de la resolución del Presidente del Parlamento Foral por la que se proponía al Rey, en virtud de una discutida aplicación del procedimiento de investidura automático, el nombramiento del Presidente de la Diputación Foral de un candidato sobre el que la Cámara no se había llegado a pronunciar en momento alguno ${ }^{23}$. No parece preciso abundar en exceso en un caso sobre el que tanto se ha escri-

Parlamento Catalán, de medidas de adecuación del ordenamiento urbanístico de Cataluñan - S.T.C. 259/1988, de 22 de diciembre-; Decreto 151/1984, de 13 de septiembre de la Junta de Galicia por la que se establecían medidas de fomento y promoción de empresas en dicha Comunidad S.T.C. $64 / 1990$, de 5 de abril—. Apuntar aquí también, como reseñamos supra, la impugnación planteada "por motivos competenciales" con arreglo al Título V de la L.O.T.C. frente al Decreto 48/1988 de 28 de abril, por el que se regulaba la pesca de arrastre de fondo en las Islas Baleares -S.T.C. 184/1996, de 14 de noviembre-. De igual forma, aunque de manera subsidiaria a la interposición de un conflicto de competencia, "Decreto 346/1981, de 10 de septiembre, del Consejo Ejecutivo de la Generalidad de Cataluña, por el que se determinan las funciones a realizar por el personal con categoría de administrativo y se amplía la escala de puestos de trabajo de la Generalidad" - S.T.C. 54/1982, de 26 de julio-. En este caso el T.C. no entró a abordar esta específica cuestión en tanto que se habían alegado únicamente cuestiones de mera ilegalidad que corresponderían lógicamente a la vía contencioso administrativa.

19. "Resolución del Presidente de la Generalidad de Cataluña por el que se prestaba aprobación al Convenio, no fechado, adoptado por aquel con el Presidente del Consejo Regional de Murcia, relativo a la participación y cooperación en cuantas actuaciones afectaran a las aspiraciones y necesidades comunes a ambas colectividades" - - S.T.C. 44/1986, de 17 de abril一.

20. "Resolución del Presidente del Parlamento Foral de Navarra de 25 de agosto de 1983 por la que se proponía al Rey el nombramiento del Presidente de la Diputación Foral "-S.T.C. 16/1984, de 6 de febrero-. La impugnación se tramitó aquí acumuladamente al recurso de amparo interpuesto por G. Urralburu Tainta, candidato del Grupo Socialista a la Presidencia de la Diputación y a la sazón Presidente de la misma tras la sentencia del T.C. que anuló la propuesta de nombramiento, y retrotrajo el proceso de elección al momento inmediatamente anterior a la celebración de la cuarta votación de investidura.

21. "Acuerdo de la Mesa del Parlamento Vasco de 9 de febrero de 1999 mediante la que se autorizaba al Parlamento del Kurdistán en el exilio la celebración de sesiones de trabajo en la sede del Parlamento Vasco" - A.T.C. 265/1999, de 10 de noviembre-.

22. "Acuerdo de Colocación por la Consejería de Política Territorial y Obras Públicas del Gobierno Vasco de señales de circulación en vías interurbanas del País Vasco" -A.T.C. 54/1983, de 16 de febrero-. En este supuesto la retirada final de las señales determinó el desistimiento del recurso.

23. Como es sabido, la L.O. $1 / 2001$, de 26 de marzo, de reforma de la L.O.R.A.F.N.A. eliminaría la (eventual) automaticidad del procedimiento de investidura, determinando que el transcurso de treinta días desde la primera votación de investidura sin que candidato alguno hubiera obtenido la mayoría necesaria provocaría la disolución automática del Parlamento y no la investidura del candidato del partido que hubiera obtenido un mayor número de escaños como se establecía hasta la fecha. A día de hoy, son pocas las CC.AA. que recogen, aun con ciertas diferencias, fórmulas de este tenor (Véase, Andalucía - art. 37. E.A.-, Castilla La Mancha - art. 14 E.A.-,Valencia -art. 133 del R.P.-) 
to, remitiéndonos así a los diferentes estudios doctrinales que sobre este supuesto existen. También muy destacado, aunque en este caso se trató de un supuesto de impugnación subsidiaria de un conflicto positivo de competencias, fue la impugnación del Acuerdo de la Mesa del Parlamento Vasco de febrero de 1999 mediante el que se autorizaba la celebración de sesiones de trabajo en la sede del Parlamento Vasco al denominado "Parlamento del Kurdistán en el exilio" ${ }^{24}$.

Mas en ningún momento se había presentado hasta ahora una impugnación referida a actos de tramitación de un procedimiento legislativo ya fuera, como aquí, de remisión de un proyecto legislativo o de calificación y admisión a trámite del mismo.

Todo lo más, únicamente por lo que a la resolución de la Mesa haría referencia, se habría hecho con relación a determinados actos procedentes de órganos intraparlamentarios, así, con los dos casos apuntados supra, el nombramiento del Presidente de la Diputación — Resolución del Presidente del Parlamento-, o la autorización de la utilización de la sede del Parlamento Vasco - Acuerdo de la Mesa del Parlamento-; actos, ambos, de carácter resolutorio y claros efectos jurídicos ad extra.

Muy diferentes, no obstante, del que ahora nos ocupa, por más que un importante sector de la doctrina abundaría en la ubicación indubitada de estos actos bajo dichas rúbricas.

En todo caso, parece oportuno abordar ambos acuerdos separadamente.

\section{INICIATIVA LEGISLATIVA GUBERNAMENTAL}

Con independencia de que los dos acuerdos recurridos forman parte de un mismo procedimiento, reforma del Estatuto de Autonomía (más allá de sus otras implicaciones), sustentar la condición de objeto idóneo de impugnación al amparo del procedimiento del Título $\mathrm{V}$ de la L.O.T.C. parecería revestir a priori una mayor complejidad con relación al acuerdo del Gobierno vasco, que respecto al del Parlamento, sobre la base de la posibilidad de impugnación de actos de este último a través de otros instrumentos procesales, idea en la que, sin compartirla, luego abundaremos. Aquél ejercería por medio de tal actuación su iniciativa legislativa y, obviamente, culminaría un procedimiento interno previo a la tramitación parlamentaria: la elaboración del proyecto. Esto, no obstante, no habría de determinar sin más su condición de objeto idóneo de impugnación.

La Propuesta remitida al Parlamento, como incidirá en su argumentación el Tribunal Constitucional, no es más que eso, esto es, una simple propuesta de reforma cuyo único efecto es propiciar el debate parlamentario. 
Un debate que puede en última instancia concluir en un texto específico, coincidente con el inicialmente remitido o, por el contrario, haber sido modificado bien de manera mínima o bien ampliamente, pudiendo finalizar incluso sin obtener acuerdo alguno.

Señalará así que,

"Decir que el contenido de la Propuesta del Gobierno Vasco es contrario al ordenamiento vigente, no es decir nada que no pueda decirse de cualquier norma que pretenda, justamente, la reforma de ese ordenamiento. Si la antijuridicidad se predicara, no ya de normas definitivamente instaladas en el ordenamiento, sino de simples proyectos de normas o, antes aún, de la sola intención de producir normas, entonces el cambio y la reforma serían literalmente imposibles. (..) El hecho de que semejante iniciativa sólo pueda prosperar con éxito si antes se reforma la Constitución, tal y como sostiene el Abogado del Estado, no convierte a la "Propuesta" en sí (ni, por conexión, al Acuerdo que la formaliza) en una iniciativa inconstitucional. (..) En tanto no se agote el procedimiento parlamentario iniciado con la remisión de la "Propuesta" no cabe más inconstitucionalidad, en su caso, que la que resulte de la infracción de las normas que disciplinan ese procedimiento. La Propuesta del Ejecutivo Vasco no es capaz de dar otro efecto que el de dar inicio a un debate parlamentario (..) En fin, en el estadio actual del proceder parlamentario no puede anticiparse ningún resultado normativo $y$, en consecuencia, todo posible juicio es, inevitablemente, prematuro (..) y a propósito de la alegada necesidad de que previamente se reforme la Constitución, nada impide que, advertida por la Cámara esa necesidad, ella misma decida reconvertir la "Propuesta" en una iniciativa propia de reforma de la Constitución, para lo que está constitucionalmente legitimada (arts. 166 y 87.2 CE)" (F.J. 6)

Los efectos del ejercicio de esta iniciativa exclusivamente ligados a su tramitación parlamentaria no tendrían mayores efectos ad extra que "una dimensión política inherente a su condición de desencadenante de un debate parlamentario".

De esta forma,

"La "Propuesta" impugnada, en tanto que iniciativa de debate parlamentario, agota todos sus efectos en esa sola condición, y, como tal, no puede ser objeto de otro juicio que el de oportunidad o conveniencia, para el que este Tribunal es manifiestamente incompetente, por estar reservado a los propios parlamentarios y, mediatamente, a sus representados. (..) El enjuiciamiento jurisdiccional queda naturalmente descartado, pues, por definición, supuesta la formal constitución e integración del Gobierno y de la Cámara, así como las formalidades de tiempo y lugar imprescindibles para que ésta sea tal, y no un mero agregado de individuos, el debate es absolutamente libre en su contenido. (..) La necesaria defensa jurisdiccional del ordenamiento no puede verificarse sino cuando cabe hablar propiamente de infracciones normativas, sólo susceptibles de ser causadas, obviamente, por normas, y nunca por proyectos o inten- 
ciones normativas que, en cuanto tales, pueden tener cualquier contenido. La jurisdicción puede reaccionar contra la forma jurídica que resulte de esas intenciones, pero la intención misma y su debate o discusión son inmunes en una sociedad democrática a todo control jurisdiccional, singularmente si el debate se sustancia en un Parlamento, sede privilegiada del debate públicon (F.J. 6)

No tiene aquí validez el argumento perverso, que se utilizaría igualmente con relación al acuerdo de la Mesa, que se resumiría en la máxima "la infracción crea la resolución". Todo lo contrario. Únicamente si nos encontramos ante una resolución puede hablarse a continuación de la eventual existencia de una infracción constitucional.

\section{ACUERDO DE CALIFICACIÓN DE LA MESA}

Si bien sostener la caracterización del acuerdo del Gobierno Vasco como objeto idóneo del proceso de impugnación del Título $\mathrm{V}$ de la L.O.T.C. parecía un puro ejercicio de malabarismo, con relación al acuerdo calificador de la Mesa, como ya anticipamos antes, entrarían en juego otra serie de cuestiones que, para un sector de la doctrina, facilitarían tal tarea hasta el extremo de parecer poco menos que superflua toda labor exegética. Ello más allá de que los argumentos antes apuntados con relación a la propia caracterización de la propuesta (simple iniciativa articuladora del debate) cabría darlos aquí por reproducidos.

De esta forma, el hecho de que existiera una amplia jurisprudencia con relación a acuerdos adoptados por los órganos parlamentarios (hablamos, obviamente, de recursos de amparo interpuestos de conformidad con el art. 42 de la L.O.T.C.) parecía llevar indefectiblemente a tal conclusión siguiendo sus pautas interpretativas.

Así lo sostuvo un sector de la doctrina sobre la base de la existencia de una declaración de conocimiento y voluntad en la decisión de la Mesa de la tramitación incorrecta de la propuesta, y asimismo en el propio papel de éstas con relación al control, no meramente formal, de las propuestas - en genérico-, en la que poder proceder a una verificación liminar de la conformidad a derecho ${ }^{25}$. A mayor abundamiento, se apelará a la S.T.C. 76/1994, de 14 de marzo, caso que, recordemos, había tenido origen en la decisión del propio Parlamento vasco de inadmitir a trámite una proposición de ley de iniciativa legislativa popular que planteaba una reforma constitucional encubierta; este supuesto, permitirá a T.R. Fernández señalar que "la cuestión es tan clara que ni el propio Parlamento Vasco, vinculado como está a sus propios actos anteriores contra los que a nadie es lícito volver (venire con-

25. Ver, así, FERNÁNDEz, T.R., "Sobre la viabilidad jurídica de la impugnación...", cit., pág. 21 y ss; González-Trevijano, P., "Sobre la viabilidad procesal de la impunación..", págs. 30 y ss. 
tra factum proprium non licet), podría discutirla legítimamente ${ }^{26}$. La inequívoca inconstitucionalidad de la propuesta habría de venir, conforme esta interpretación, en la obligada inadmisión a limine por parte de la Mesa del Parlamento Vasco.

No obstante, como reseñará el Alto Tribunal con relación a aquella traslación apuntada, no es posible realizar sin más la misma, y no ya siquiera porque ni la propia terminología de las previsiones de los arts. 42 y 76 de la L.O.T.C. serían diferentes (aquél habla de "decisiones o actos sin valor de ley emanados de las Cortes o de cualquiera de sus órganos o de las Asambleas legislativas de las CC.AA., o de sus órganos" mientras que éste lo hará de "disposiciones normativas sin fuerza de ley y resoluciones emanadas de cualquier órgano d las Comunidades Autónomas"), sino por la propia "sustantividad y caracterización" de los dos procesos.

Apuntará así el Tribunal:

"En efecto, a través del recurso de amparo contra los Acuerdos de las Mesas de la Cámara de calificación y admisión a trámite de una iniciativa legislativa lo que se pretende es preservar el derecho de participación de los sujetos legitimados a intervenir en el procedimiento parlamentario frente a unos actos únicamente relevantes ad intra, esto es, cuya eficacia se circunscribe exclusivamente a este procedimiento y a los sujetos legitimados para intervenir en él, careciendo de relevancia alguna ad extra. Por su parte, el proceso impugnatorio del título V LOTC se inserta en el marco de las relaciones y mecanismos de control entre el Estado y las Comunidades Autónomas, no pudiendo constituir objeto del mismo los Acuerdos de las Mesas de la Cámara de calificación y admisión a trámite de una iniciativa legislativa, por desplegar éstos sus efectos únicamente en el estricto ámbito del procedimiento parlamentario del que forman parte y para los sujetos legitimados a participar en el mismo, presentando sólo relevancia ad extra, si el procedimiento legislativo concluye con la aprobación de la ley, en cuyo caso han de ser combatidos a través de la impugnación de ésta por los procesos constitucionales al efecto establecidos. En otras palabras, los posibles vicios en los que puedan incurrir los actos que se insertan en la tramitación del procedimiento legislativo carecen de toda relevancia ad extra en tanto éste no concluya con la aprobación de la ley que lo culmine" (F.J. 7)

No es posible así, como señalaría aquél, lo que vendría en denominarse "recurso de amparo por sustitución", esto es, la invocación por el Gobierno de derechos de los que no sería titular y que corresponderían a los parlamentarios legitimados en el procedimiento legislativo.

En el mismo sentido, y con relación a la eventual inconstitucionalidad de los actos parlamentarios, éstos sólo cobrarían relevancia, 
"Cuando concluyen con una resolución, disposición o acto que se integra en el Ordenamiento (y deberá verificarse con motivo del juicio de constitucionalidad que eventualmente se inste respecto de esa disposición, resolución o acto), o cuando, sin finalizar el procedimiento en el que se insertan, producen una lesión inmediata de derechos fundamentales de los sujetos legitimados para participar en el procedimiento. Aquel control se verificará por vía del recurso y de la cuestión de inconstitucionalidad; éste mediante el recurso de amparo" (F.J. 8)

Si bien para los magistrados disidentes resulta paradójico la posibilidad de negar, a efectos impugnatorios, la condición específica de "resolución" al acuerdo de la Mesa en tanto que sí se le atribuiría en el supuesto de que se hubiera interpuesto un recurso de amparo por la presunta vulneración del art. 23 C.E., los supuestos no son equiparables.

Para ambos acuerdos (no sólo el del Parlamento) habría de descartarse la posibilidad de impugnación conforme tal procedimiento previa la finalización del procedimiento puesto que,

“El título V, en un entendimiento sistemático de la Ley en la que se incluye, establece un procedimiento de control de constitucionalidad de disposiciones y resoluciones imputables a la Comunidad Autónoma por conducto de los órganos expresivos de su voluntad institucional, supuesto en el que manifiestamente no pueden comprenderse los actos que se insertan en un procedimiento de gestación (incierta) de esa voluntad. Y debe también excluirse una vez finalizado el procedimiento, si éste lo hace con una norma con rango de ley" (F.J. 8)

En consecuencia, y más allá de eventuales interpretaciones interesadas que han pretendido ver en el Auto cuestiones diferentes, se adolece aquí de un objeto idóneo de impugnación al amparo de este procedimiento ${ }^{27}$.

Ahora bien, señalar esto no implica, como el propio Tribunal aclara en su resolución, que la Mesa haya ejercido en términos constitucionalmente adecuados su facultad de calificación y admisión a trámite, que se haya respeta-

27. No coincidimos con aquellas interpretaciones que parecen haber visto en el Auto del Tribunal Constitucional una suerte de "aval" al proyecto que sane, no ya el contenido propio del proyecto, sino la propia tramitación procedimental. Así, M. URÍA señaló recientemente, entre otras apreciaciones, en un artículo publicado bajo el sugerente título "No es tiempo de vetos", que estamos ante una propuesta perfectamente estatutaria que se atiene al procedimiento y a las reglas previstas para su elaboración, presentación y discusión en el Parlamento", EL PAÍs 16 de mayo de 2004. Pero lo cierto es que el Tribunal Constitucional no entró, lógicamente, en estas cuestiones, sino que se limitó a señalar en su Auto que en en este momento de la tramitación procedimental la impugnación interpuesta adolece de objeto procesal idóneo de impugnación. Únicamente eso. Es por ello que también sorprende que dicho Auto pueda servir de aval de la "Constitucionalidad" de la Propuesta, como así sugirió la Portavoz del Gobierno Vasco y Consejera de Cultura, M. Azcarate, al señalar que "el auto del T.C. en ninguna parte dice que el contenido de la actual propuesta, de aprobarse, fuera inconstitucional, tal y como los medios de comunicación informaron profusamente. ¿Quién mintió a los medios cuando facilitó la información y por qué?", "El Estado que nunca existio», EL PAÍs, 13 de mayo de 2004. 
do la reserva de Reglamento Parlamentario o que no se hayan podido vulnerar en su caso las previsiones del art. 23.2 de la norma suprema.

Si uno de los argumentos utilizados en orden a la inadmisión a trámite del recurso, como hemos visto, no era otro que la ausencia de relevancia ad extra del mismo, parece claro senso contrario que cuestión bien diferente sería la incidencia o relevancia ad intra de uno de estos acuerdos. Hablamos, lógicamente, con relación al ius in officium de los parlamentarios, del acuerdo de calificación y admisión de la Mesa del Parlamento Vasco, con los que se pudo incurrir en un auténtico fraude procedimental ${ }^{28}$. Relevancia ad intra que se compaginaría, obvio es señalar, con el eventual control, este externo, que podría ejercer el Tribunal Constitucional.

Así pues, habría que plantearse la posibilidad de que hubiera sido interpuesto un recurso amparo, de conformidad con el art. 42 L.O.T.C. ${ }^{29}$, por parte de alguno o algunos parlamentarios, tras la solicitud de reconsideración planteada ante la Mesa, al poder afectar a su ius in officium la elección del procedimiento en virtud del acuerdo de calificación y admisión, en la medida que no es disponible sino obligatorio y que podría hacer variar, perjudicar y lesionar los derechos de los parlamentarios en función del procedimiento a seguir. Esa interpretación la defendería P. González-Trevijano al señalar que "la acción irregular de la Mesa ha encadenado otra violación más, pues se incide directamente en los derechos, así violados, de los representantes parlamentarios de la Cámara Vasca (..) Una acción representativa de los parlamentarios vascos que habría de producirse dentro de los límites fijados por la Constitución, el respectivo Estatuto de Autonomía y el Reglamento Parlamentario. Unos derechos constitucionales que les habrían sido privados a los mismos por la irregular conducta calificadora de la Mesa" hecho que le lleva a apuntar que existe la "oportunidad de que éstos pudieran interponer, por tales causas, su pertinente recurso de amparo frente al acuerdo de la Mesa al hilo de las argumentaciones señaladas ${ }^{30}$. Recordemos que aquélla fue solicitada por los Grupos Popular y Socialista Vascos, defendiendo la inadmisión a trámite de la Propuesta por flagrante carácter inconstitucional y estatutario, y requiriendo que la Mesa del Parlamento pidiera al Gobierno la totalidad de antecedentes necesarios, así

28. Con relación a los problemas de la calificación y admisión a trámite, ARCE JANARIZ, A., "Calificación y admisión a trámite en los procedimientos parlamentarios", Revista Española de Derecho Constitucional, $\mathrm{n}^{\mathrm{o}} 29,1990$, págs. 9 a 116; también de este autor, "iOverruling en la jurisprudencia constitucional sobre el trámite parlamentario de admisión?", Parlamento y Justicia Constitucional, Aranzadi, Madrid, 1997, págs. 365 a 378.

29. Sobre este específico punto, véase, DE LA PEÑa Rodríguez, L., Derecho parlamentario espanol y Tribunal Constitucional, Comares, Granada, 1998, PULIDo QuECEDO, M., El acceso a los cargos y funciones públicas, Cívitas, Madrid, 1992, esp. págs. 464 a 501.

30. A mayor abundamiento destacará el carácter inmotivado del Acuerdo de la Mesa, para terminar señalando que "Se hierra, en fin, en el Escrito de calificación de la Mesa del Parlamento vasco (..) calificándolo como procedimiento de reforma estatutaria, lo que es, por encima de todo, un procedimiento de revisión constitucional, y por órgano manifiestamente incompetente, al margen de los quebrantamientos constitucionales y reglamentarios apuntado", "Sobre la viabilidad procesal de la impugnación...", cit., págs. 33/34. 
como la suspensión de la tramitación hasta la remisión de dicha documentación. Estas solicitudes serían finalmente rechazadas por la Mesa, acordándose la prosecución de la tramitación de la iniciativa. Con posterioridad y tras la votación por separado de las enmiendas a la totalidad presentadas a la Propuesta de Reforma, los Grupos Popular y Socialistas presentaron nuevo escrito de reconsideración y queja en el que se solicitaba la votación en la Comisión de Instituciones e Interior conforme a lo prevenido en el art. 106.2 del Reglamento del parlamento Vasco. La Mesa acordaría finalmente no tomar en consideración tales escritos.

Si bien no hay duda que este acuerdo de la Mesa del Parlamento si hubiera sido un objeto procesal idóneo de un recurso de amparo en orden a ser admitido a trámite, parece dudoso no obstante sostener que un "acuerdo de admisibilidad" de la Mesa, aunque impugnado por quienes se habrían opuesto a él, deviniera finalmente en una resolución del Tribunal Constitucional que terminara afirmando la vulneración del art. 23.2 C.E. No conocemos precedente alguno en tal sentido pese a que desde la Abogacía del Estado así se señaló en la impugnación, mas sin citar referencia concreta alguna.

\section{A MODO DE REFLEXIÓN FINAL}

El criterio adoptado por el Tribunal Constitucional a la hora de inadmitir a tramite esta impugnación ha impedido hacer efectivo ese conocido aforismo anglosajón, hard cases make bad law, en tantas ocasiones cierto. Haber aceptado la posibilidad de interponer un recurso de este tipo frente a los acuerdos impugnados, hubiera abierto indudablemente una caja de Pandora de repercusiones inimaginables dentro del juego de relaciones entre el Estado y las CC.AA.

Las distorsiones generadas por el denostado, y ya desaparecido, recurso previo de inconstitucionalidad contra proyectos de Estatutos de Autonomía y leyes orgánicas, que sirvió esencialmente en sus escasos años de vigencia de instrumento paralizador de reformas legislativas ${ }^{31}$, se verían aquí multiplicadas peligrosamente ${ }^{32}$.

31. La decisión de suprimir esta figura procesal (Proposición de L.O. derogatoria del Capítulo II del Título VI de la L.O.T.C.) fue también recurrida, en virtud de recurso previo, desestimándose el mismo por la S.T.C. 66/1985, de 23 de mayo. Para la comprensión de esta figura procesal y su problemática, véase, VEGA GARcía, A.S. de, "Acerca del recurso previo de inconstitucionalidad", Revista de las Cortes Generales, no 23, 1991; Ṕ́rez RoYo, J., "Crónica de un error: el recurso previo de inconstitucionalidad contra leyes orgánicas", Revista Española de Derecho Constitucional, no 17, 1986. Fuera de nuestras fronteras, G. Rolla, también desde un planteamiento negativo se refería a este recurso en unos términos ciertamente significativos: "il ricorso preventivo: una competenza anomala", Indirizzo político e Tribunale Costituzionale in Spagna, Napoli, 1986, págs. 160 a 184.

32. Señaló J. Pérez Royo, antes de la decisión del T.C., que la admisión a trámite del recurso hubiera supuesto la mutación de la naturaleza del Tribunal Constitucional convirtiéndolo en un censor parlamentario, "Juez de la constitucionalidad de la ley o censor parlamentario?", EL PAIS, 6 de enero de 2004 
Resulta evidente que la admisión de esta precoz y preventiva impugnación con relación a estos actos de tramitación, al amparo de este mecanismo procesal, sería escasamente respetuosa con el propio funcionamiento del juego político democrático.

La discusión parlamentaria se vería aquí indefectiblemente afectada con la aceptación de un instrumento procesal cuya dimensión temporal revestiría sin duda una indudable potencialidad obstruccionista ${ }^{33}$. Aparte de las propias y evidentes implicaciones que conllevaría respecto de aquél, tendría el agravante de sús consecuencias suspensivas ${ }^{34}$, en suma, la "hibernación" del procedimiento legislativo ${ }^{35}$; haya de obtenerse o no en éste, en última instancia, la famosa evidencia Benthamtiana surgida tras las chispas del debate.

Quizá seria interesante, en sustento de esta idea, traer a colación el juicio que tan adecuadamente reflejara la exposición de motivos de la L.O. 4/1985, de 7 de junio, por la que se derogó el Capítulo II del Título VI de la L.O.T.C., esto es, el recurso previo de inconstitucionalidad. Se señalaba aquí que este recurso no había sido sino un "factor distorsionador de la pureza del sistema de relación de los poderes Constitucionales del Estado, con consecuencias inesperadas y metaconstitucionales en la ultima fase de procedimiento de formación de la Ley" o, cuando, de igual forma, apuntaba que "El Tribunal Constitucional, por su parte, órgano jurisdiccional, y, por tanto, alejado de los avatares políticos de la practica parlamentaria, se ve lanzado a una función que no responde al sistema de relación de poderes que la Constitución establece, interviniendo en el procedimiento de formación legislativa aun antes de que la voluntad parlamentaria se haya configurado definitivamente". El paralelismo sería claro. La incidencia, muy superior.

No estaríamos aquí siquiera hablando de un texto definitivamente formado al haber finalizado su tramitación parlamentaria correspondiente, obte-

33. Sobre esta cuestión, aunque respecto del antiguo recurso previo (reflexión trasladable al supuesto que nos ocupa), J. PÉrez Royo señalaba, tras destacar que un sistema de control de constitucionalidad preventivo sólo sería congruente con unos plazos muy breves para dictar sentencia, que la interposición de un recurso previo contra un ley orgánica aprobada entre el primer y segundo año de la Legislatura se resolvería en vísperas de las siguientes elecciones generales, mientras que los interpuestos a partir de la mitad de la Legislatura serian resueltos con casi total seguridad, después. Suficientemente ilustrativo. "Crónica de un error: el recurso previo de inconstitucionalidad contra leyes orgánicas", cit., págs. 159 a 162.

34. Esta cuestión no se deja de lado en los votos particulares discrepantes emitidos. Así, en el formulado por G. Jiménez SÁNChez, R. García CALVo y J. Rodríguez ZaPATa, se incidirá en este punto, aunque apuntando como contrapeso a la exorbitante facultad atribuida al Gobierno, la posibilidad de "inadmitir a limine las impugnaciones que pudieran calificarse de abusivas o ejercitadas desviadamente con una finalidad indirecta o torcida" señalando en todo caso que estas apreciaciones "fuerza es observarlo, situarían a este tribunal en los aledaños de la política"; la conclusión del planteamiento de cualquier forma, y una vez defendida la condición de resoluciones de los acuerdos impugnados, sería que en el presente supuesto "el examen de algunos de los motivos de impugnación de los Acuerdos adoptados por el Gobierno y por la Mesa del Parlamento Vascos revela que no se pretende de este Tribunal la utilización de cánones de constitucionalidad que no haya empleado ya en ocasiones anteriores".

35. Nos servimos aquí de la expresión utilizada por A.S. DE VEGA al abordar la disfuncionalidad del desaparecido recurso previo, "Acerca del recurso previo de inconstitucionalidad", cit., pág. 62 
niendo la mayoría necesaria para su aprobación, y aguardándose únicamente su fase de integración de la eficacia, como sucedía con aquel recurso ${ }^{36}$, sino ante un proyecto, un incipiente documento de trabajo para la hipotética elaboración de una ley ${ }^{37}$, del que se desconoce su contenido y extensión última una vez finalicen los diferentes trámites parlamentarios. $O$, incluso, si llegará a tener contenido alguno ya que puede no obtener el apoyo necesario para su aprobación.

Ello supondría otorgar al Gobierno una suerte de "veto suspensivo" con relación a las diferentes propuestas legislativas que en el ámbito autonómico pudieran tomarse, antes de alcanzar maduración normativa alguna, reconociéndosele en consecuencia un poder infinitamente mayor que el que le otórgaba aquel artículo 143 del Anteproyecto Constitucional, rápidamente desechado durante la tramitación constituyente ${ }^{38}$. La desaparición de esta previsión del Informe de la Ponencia - que había sido adoptada por influencia de otros textos constitucionales de nuestro entorno, así, la Constitución italiana por ejemplo-, devino de la aceptación de varias enmiendas que incidían lógicamente en su contradicción con el principio de autonomía y autogobierno, así como en la alteración del equilibrio y poderes constitucionales que produciría su inclusión.

Malabarismos o voluntarismos a un lado, las previsiones del Título $\mathrm{V}$ de la L.O.T.C. no permitían una extensión del objeto procesal de tal forma que el propio procedimiento legislativo hubiera de verse sujeto a su régimen. $\mathrm{Ni}$ siquiera para los acuerdos de calificación de la Mesa sobre los que parecía existir un mayor grado de incertidumbre sobre la base de una traslación mimética de las previsiones del concepto resolución, en sentido amplio, de otros instrumentos procesales. Mas en cualquier caso, no resulta equiparable la presentación de un recurso de amparo frente a acuerdos vulneradores de derechos fundamentales, concretamente los del art. 23 C.E., que la impugnación que dio origen a este procedimiento. La excepción deriva allí del bien jurídico protegido. A mayor abundamiento, como ya vimos, tampoco existiría concordancia terminológica entre unas y otras previsiones.

36. La interposición del recurso resultaba posible tras la tramitación en ambas Cámaras del proyecto de L.O., y una vez que el Congreso se hubiera pronunciado en su caso sobre las enmiendas propuestas en el Senado; el procedimiento seguiría su curso cuando el pronunciamiento del T.C. declarara la inexistencia de la inconstitucionalidad alegada.

37. Recuérdese la argumentación recogida en la S.T.C. 124/1995, de 18 de julio, en la que se expresaría esta idea, con ocasión del recurso de amparo interpuesto contra sendas Resoluciones de la Mesa del Parlamento de Murcia por la que se declaraba la inadmisión a trámite de una proposición de ley de reforma de la Ley de Régimen Local de la Región de Murcia (vid. esp. F.J. 4)

38. Recordemos que este artículo señalaba que "Los textos aprobados por la Asamblea del Territorio Autónomo serán inmediatamente comunicados por el Presidente de éste al Gobierno. Éste, en el plazo de un mes, podrá solicitar de la Asamblea una segunda deliberación sobre todos o algunos de los extremos del mismo. En este caso, el texto para ser aprobado como ley territorial, requerirá la votación favorable de la mayoría absoluta de los miembros de la Asamblea (..)", Boletin Oficial de las Cortes, $\mathrm{n}^{\circ}$ 44, de 5 de enero de 1978. 
Nuestro ordenamiento contiene suficientes instrumentos para garantizar el equilibrio del Estado de las Autonomías sin necesidad de subvertir este procedimiento hasta el extremo de hacer permeable la discusión parlamentaria a la interposición de esta suerte de vetos suspensivos. Pero lo que no es posible en ningún caso es anticipar el hipotético control (verificado, llegado el caso, y el momento procesal oportuno, por medio del recurso de inconstitucionalidad) a través de una impugnación al amparo del Título $\mathrm{V}$ de la L.O.T.C., pues difícilmente guardaría coherencia con la lógica del sistema de control diseñado por el Constituyente. 